\title{
Acute toxic effects of chlorpyrifos and indoxacarb on dorsal pars medialis of telencephalon and swimming behavior of a catfish, Heteropneustes fossilis
}

\author{
Ajeet Kr. Mishra, Anita Gopesh, K. P. Singh* \\ Department of Zoology, University of Allahabad, Prayagraj, India
}

\begin{tabular}{l}
\hline ARTICLE INFO \\
\hline Article history: \\
Received on: January 19, 2021 \\
Accepted on: March 08, 2021 \\
Available online: May 10, 2021
\end{tabular}

Key words:

Chlorpyrifos, indoxacarb, telencephalon, swimming behavior, $H$. fossilis

\begin{abstract}
The current study is an attempt to compare the potential effects of acute exposure of two widely used insecticides, chlorpyrifos (CPF) and indoxacarb (IDC), on the histopathology of fish brain and its impact on locomotory behavior of a catfish, Heteropneustes fossilis, as a non-target species. In our study, fishes of lentic habitats $(n=12 /$ group $)$ were exposed to LC $_{50}$ doses of CPF $(1.92 \mathrm{mg} / \mathrm{l})$ and IDC $(0.075 \mathrm{mg} / \mathrm{l})$ for 96 hours. During the experiment, locomotory activities of control and exposed fishes ( $n=6 /$ group) were recorded at a regular period by ANY-MAZE software (Stoelting Co., Chicago, IL). At the endpoint of 96 hours, fishes were sacrificed for the histopathological study of the telencephalon region of the brain. The CPF toxicity induced highly degenerative changes and vacuolization in the neuronal cells of dorsal pars medialis (dDm) of the telencephalon, and substantial disturbances in the swimming pattern of mobile and immobile episodes, rotational locomotory movements; whereas IDC induced mild pathological changes in the $\mathrm{dDm}$ of telencephalon of fish brain, and irregular locomotory behavior in H. fossilis when compared to the control group. Thus, the present study concludes that IDC was found to be less toxic than CPF. Hence, IDC could be an alternate choice of the $\mathrm{CPF}$ at equal concentrations.
\end{abstract}

\section{INTRODUCTION}

Chlorpyrifos(CPF) and indoxacarb(IDC)aremoderately hazardous pesticides that belong to organophosphate and oxadiazine groups. These insecticides are commonly used to control the foliar insects in a variety of agriculture crops. The mechanism of action of CPF leads by the inhibition of acetylcholinesterase (AChE) activity in the neuromuscular junction [1-3], whereas IDC blocks sodium ion channels in the nerve cells [4,5]. After application in the agricultural fields, these insecticides' residue ultimately reached into the nearby aquatic bodies through surface run-off and adversely affected non-target aquatic organisms, including fishes. These organisms are sensitive bio-indicators for the aquatic health of an ecosystem. Any environmental changes in the aquatic ecosystem may lead to subtle changes in the swimming (horizontal and vertical) and respiratory behavior of resident fishes (gill

*Corresponding Author

K. P. Singh, Department of Zoology, University of Allahabad, Allahabad, India.E-mail :kpsald29@gmail.com,kps29@rediffmail.com breathers or air breathers). In these fishes, the depletion of oxygen or hypoxic state in the lotic and lentic water triggers physiological (respiratory)-mediated mechanisms at cellular, biochemical, and molecular levels, leading to abnormal pathology in some tissues or organs. Similarly, acute or chronic exposure to CPF or IDC (as a stressor) may also induce adverse effects on different anatomical and physiological systems of the fishes.

The majority of the literature is available on CPF toxicity (acute, sub-chronic, or chronic)-induced histopathological changes in gills, liver, kidney, and skin; however, limited literature is available on different brain regions of fishes [6-8], Although some literature is available on the effects of CPF on different brain regions of fishes, including the telencephalon but literature is almost silent on IDC-induced toxicity on histopathological changes in the telencephalon region of fish brain.

The brain plays a regulatory role in fish physiology, especially when pesticides are involved in their mode of action in the nervous system $[9,10]$. The telencephalon is the most peculiar part of the teleost's brain, consisting of rostrally located olfactory 
bulbs, olfactory lobe, and more caudally cerebral hemisphere. The outer layers or roof of the cerebral hemisphere, the pallium, may be equivalent to mammalian neocortex with a lack of distinct sixlayered cortex or even-layered structure [11-13]. The area dorsalis telencephali (D) and ventral telencephali (V) are considered to be homologous approximately to the pallium and subpallium of other vertebrates [14-16]. The telencephalon in fish is most probably equivalent to the hippocampus and amygdala in mammals $[17,18]$. Some behavioral studies have demonstrated that telencephalon helps in the processing of visual inputs and also plays a significant role in feeding, defense, schooling, and aggressive and reproductive behavior [19-22]. Additionally, telencephalon is also involved in the manifestation of learning and memory and spatial learning [23-25].

The subtle changes in the behavior of fishes by the addition of any Xenobiotic compounds are an indicator of environmental suitability $[26,27]$. As fishes and some aquatic insects are essential aquatic biological indicator, hence any change in the behavior of fishes and aquatic insects also indicates deterioration of water quality or the health of the aquatic body which is an indicator of environmental suitability and ecological risk [28,29]. Previously, several investigators have reported substantive changes in the swimming/locomotory behavior of fishes after exposure to insecticides in general and CPF in particular under laboratory conditions [30-33], but limited literature is available on IDCinduced behavioral changes in fishes $[4,5,34]$.

In light of the above views, the present study was undertaken to evaluate the acute toxic effects of CPF and IDC on histopathological changes of the telencephalon of the fish brain and swimming/ locomotory behavior of facultative air-breathing Asian catfish, Heteropneustes fossilis, in the laboratory environment.

\section{MATERIALS AND METHODS}

\subsection{Experimental Design}

Live specimens of $H$. fossilis were collected from local unpolluted ponds of Prayagraj, Uttar Pradesh, India, and transported under a mild anesthetic condition to the laboratory to minimize handling and transportation stress. These fishes were segregated according to standard length $(15.53 \pm 0.42 \mathrm{~cm})$ and weight $(33.09 \pm 0.78$ g). After dip treatment with $0.1 \% \mathrm{KMNO}_{4}$, fishes were placed in a large-sized plastic pool $(121 \times 45 \times 50 \mathrm{~cm})$ containing dechlorinated tap water (120 l) for acclimatization for 15 days under standard laboratory conditions (room temp, $24^{\circ} \mathrm{C} \pm 2{ }^{\circ} \mathrm{C}$; water temp, $23^{\circ} \mathrm{C} \pm 2{ }^{\circ} \mathrm{C}$ ). During acclimatization and experimental period, fishes were fed daily with goat liver and commercial fish pallet, and pool water was replaced daily. After completing the acclimatization period, fishes were divided into three groups, i.e., control, CPF, and IDC treatment groups ( $n=12$ /group). The selected fishes of each group were placed in the experimental aquaria $(24 \times 12 \times 12 \mathrm{~cm})$ with a predetermined concentration of $0.192 \mathrm{mg} / \mathrm{l}$ of CPF and $0.075 \mathrm{mg} / 1$ of IDC (equivalent doses of $\mathrm{LC}_{50}$ ) under the semi-static condition for 96 hours. During the exposure period, the swimming/locomotory behavior of fishes was recorded. At the end of the exposure, fishes were sacrificed ( $n$ $=3$ ) and the brain was excised immediately, and the brain tissue was fixed in formalin for histopathological examination.

\subsection{Procedure for the Recording of Swimming/Locomotory Behavior}

Individual fish of each group were placed in a recording aquarium $(24 \times 12 \times 12 \mathrm{~cm})$ to record swimming/locomotory behavior. After the settling down of erratic movements of a fish in the recording aquarium, individual fish behavior was recorded by an Automated Video tracking device, ANY-MAZE software (Stoelting Co., Chicago, IL), for a 5-minute test period. Similarly, selected individuals $(n=6)$ of each control and exposed groups were recorded at regular time intervals, 24, 48, 72, and 96 hours.

\subsection{Procedure for Histopathological Study}

After adopting the standard procedures for histological study, paraffin blocks of the whole brain were prepared, and the entire brain was cut at $8-10 \mu$ thickness using a rotatory microtome. After stretching and de-paraffinizing the micro sections (mounted on slides) in descending alcohol grades they were finally stained with hematoxylin and eosin (H\&E) staining. The photograph of the dorsal pars medialis $(\mathrm{dDm})$ of telencephalon area of stained slides was captured by a Nikon photomicroscope at $400 \times$ magnification .

\subsection{Statistical Analysis}

All the data represented the mean \pm SEM (Standard Error Mean) values and tested the significance of locomotory behavior between control and exposed fishes using the Student's " $t$ "-test. A probability level below 0.05 was taken as statistically significant.

\section{RESULTS}

\subsection{Effects of CPF and IDC on the Behavioral Assessment of Fish}

The CPF and IDC-exposed fishes showed significant changes in the mobile and immobile episodes, with a decrease in rotational (both clockwise and anti-clockwise) movements at 24, 48, 72 , and 96 hours compared with the control fishes. The mobile episodes in CPF-exposed fishes were significantly $(p<0.05-p<$ 0.001 ) decreased at $24,48,72$, and 96 hours, whereas the same were substantially $(p<0.05)$ declined in IDC-exposed fishes at 24 hours (Fig. 1). The immobile episodes in CPF-exposed fishes were significantly $(p<0.05-p<0.01)$ increased at 24 and 48 hours, while this index was non-significantly elevated in IDC-exposed fishes (Fig. 2). In CPF-exposed fishes, clockwise and anti-clockwise rotational movements were significantly decreased $(p<0.01-p<0.001)$ at different periods $(24,48,72$, and 96 hours). Similarly, in IDC exposed fishes, these movements were significantly $(p<0.05-p<0.01)$ decreased at 24,48 , and 72 hours only (Figs. 3 and 4). These results indicate that CPF induced marked and notable changes in the stereotyped swimming movements than IDC. Overall, IDC was found less toxic than CPF at equal concentration of doses $\left(\mathrm{LC}_{50}\right)$ and time intervals (24-96 hours) as shown in Figures 1-4.

\subsection{Effects of CPF and IDC on dDm of Telencephalon Region}

After acute exposure at 96 hours, the CPF-exposed fishes showing degeneration and vacuolization highly around neuronal cells of the $\mathrm{dDm}$ of telencephalon region (Fig. 5C), while less degeneration of 


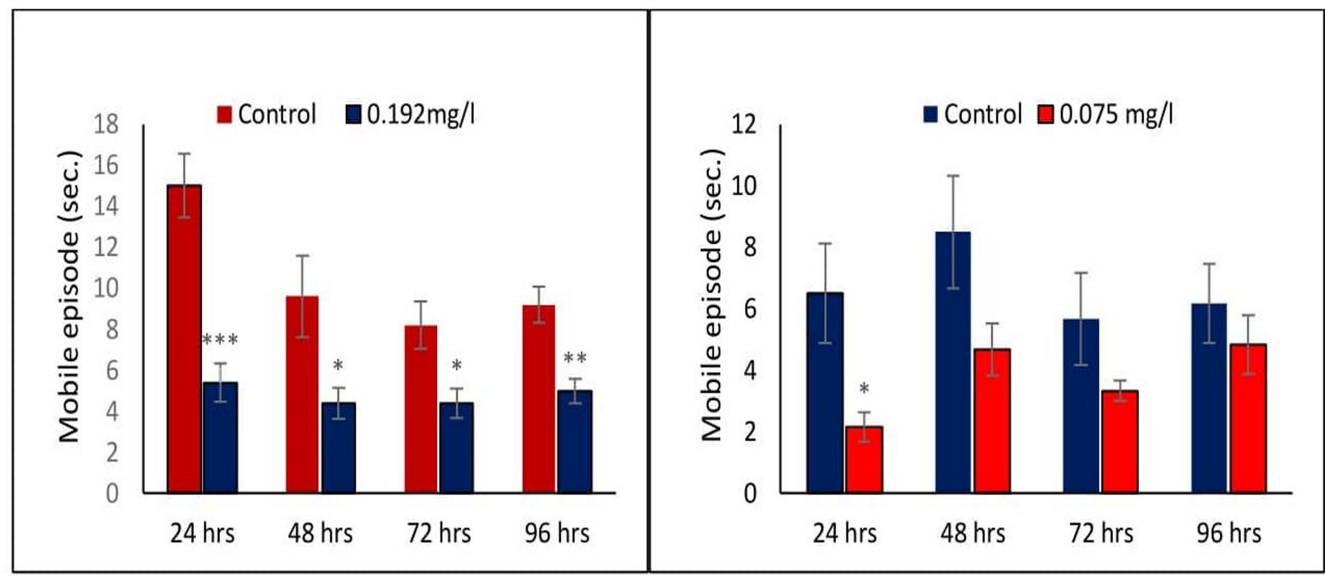

Figure 1: Effects of acute toxicity of CPF and IDC on mobile episodes at 24, 48, 72, and 96 hours at an equivalent concentration of $\mathrm{LC}_{50}$ doses. All data represent mean $\pm \mathrm{SEM}$ values. ${ }^{*}, * *$, and $* * *$ represent a level of significance at $p<0.05, p<0.01$, and $p<0.001$, respectively, after Student's " $t$ "-test.

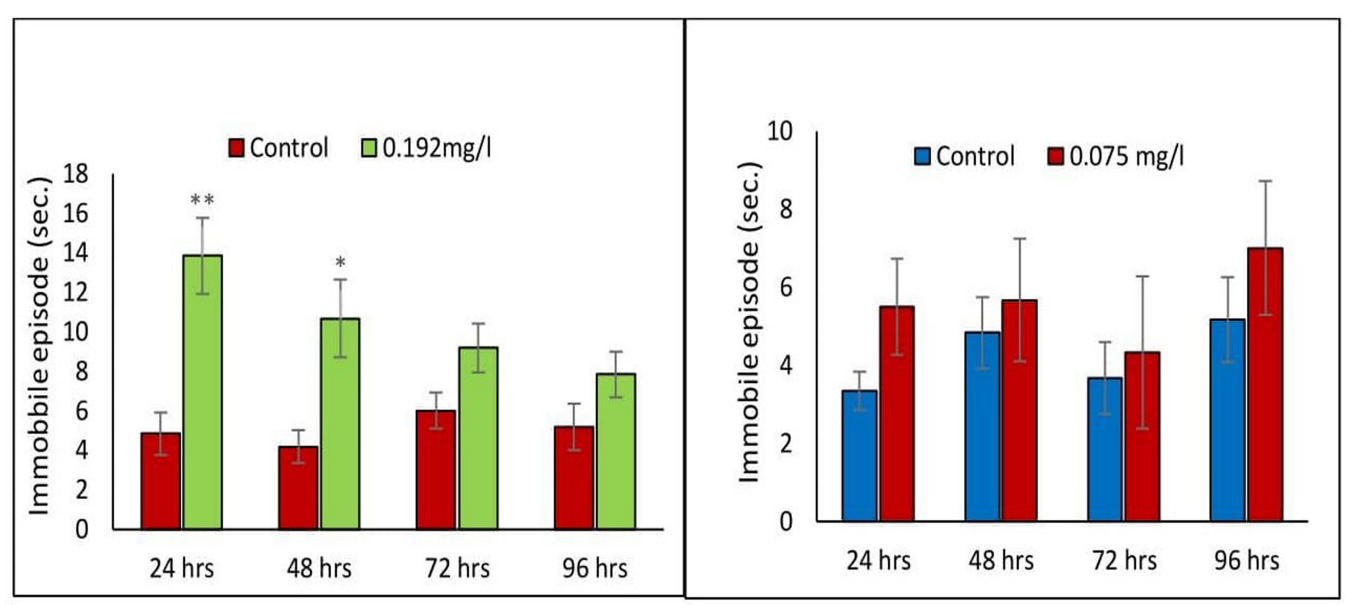

Figure 2: Effects of acute toxicity of CPF and IDC on immobile episodes at 24, 48, 72, and 96 hours at an equivalent concentration of $\mathrm{LC}_{50}$ doses. All data represent mean \pm SEM values. ${ }^{*}$ and $* *$ represent a level of significance at $p<$ 0.05 and $p<0.01$, respectively, after the Student's " $t$ "-test.

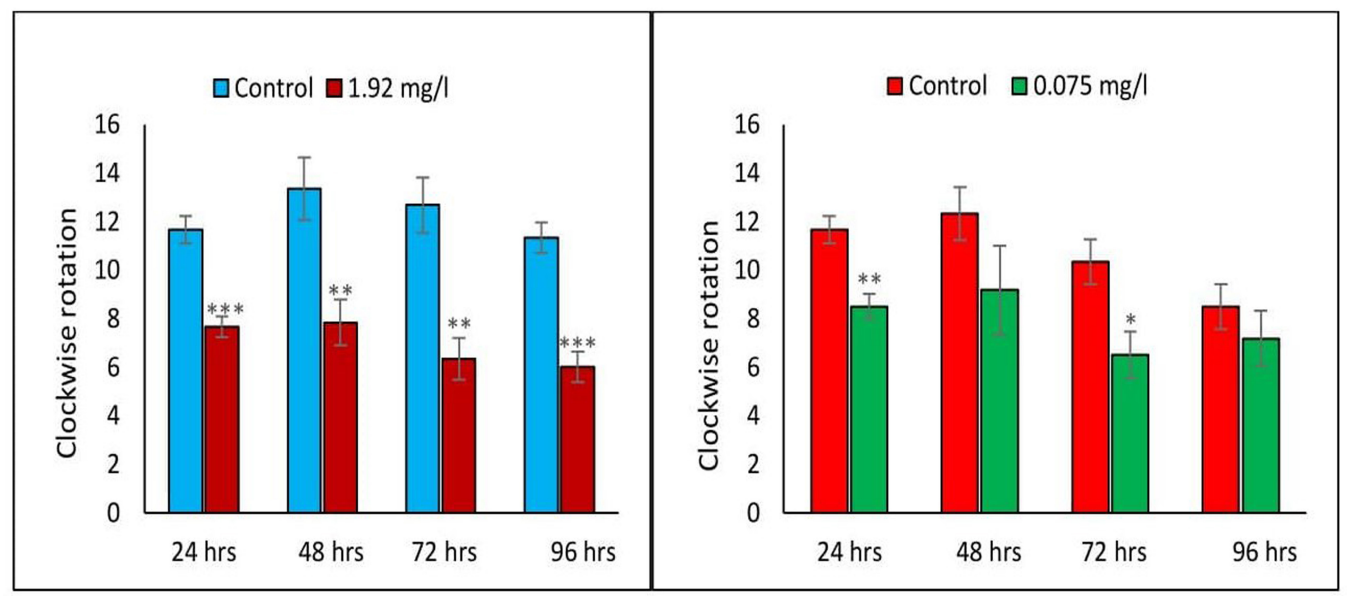

Figure 3: Effects of acute toxicity of CPF and IDC on clockwise rotational movements at 24, 48, 72, and 96 hours at an equivalent concentration of $\mathrm{LC}_{50}$ doses. All data represent mean \pm SEM values. *, **, and *** represent a level of significance at $p<0.05, p<0.01$, and $p<0.001$, respectively, after Student's " $t$ "-test. 


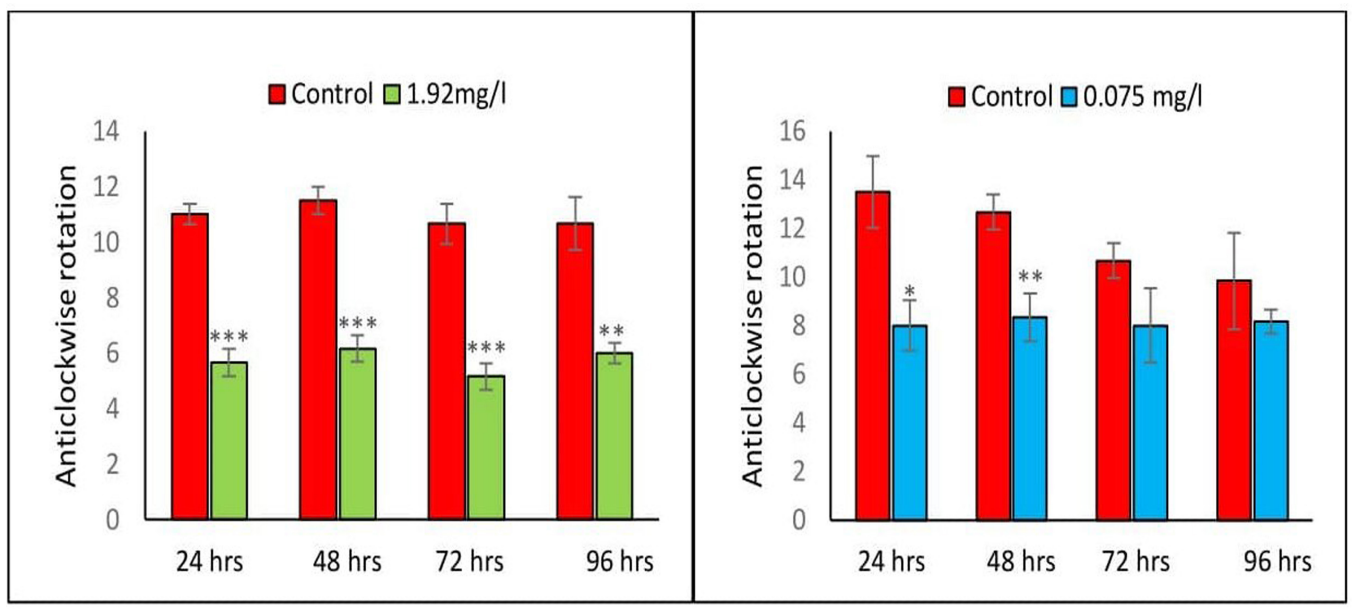

Figure 4: Effects of acute toxicity of CPF and IDC on anti-clockwise rotational movements at 24, 48, 72, and 96 hours at an equivalent concentration of $\mathrm{LC}_{50}$ doses. All data represent mean \pm SEM values. *, **, and *** represent a level of significance at $p<0.05, p<0.01$, and $p<0.001$, respectively, after Student's " $t$ "-test.

neuronal cells in the telencephalon region after exposure of IDC (Fig. 5D) when compared to control fish brain (Fig. 5A and B)

\section{DISCUSSION}

The present study revealed that acute toxicity (96 hours) of CPF and IDC induced histopathological changes in the telencephalon region of the fish brain and subsequently reduced locomotory responses, including loss of feeding and defense behavior in an air-breathing catfish, $H$. fossilis.

To assess various stressors, like microbial pathogens, toxic compounds, and nutritional and adverse environmental conditions, in both laboratory and field studies, histopathology is an essential tool to envisage the stress-encouraged structural changes in cells and tissues and has been extensively used biomarkers [35] and can also be used as bio-monitoring tools for toxicity studies [36].

Although the relationships between different ecological factor influences on the relative proportion of brain size are well established for some teleost [37]. In the present study, neuronal cell necrosis and vacuolization were observed after CPF and IDC exposure at 96 hours. This study is in agreement with other findings that reported mild necrosis and vacuolar changes of the fish brain of Channa punctatus after exposure of endosulfan at 96 hours [38], pycnosis, karyorrhexis, and karyolysis in the neuronal cells of the telencephalon, other lobes of common carp exposed to cypermethrin [39], and occasional necrosis and vacuolization of neuronal cells of telencephalon after exposure of Copper sulfate [40].

The toxicity of $\mathrm{CPF}$ and atrazine induces degeneration of Purkinje cells and granular cell loss in Cyprinus carpio [41]. Furthermore, physiological and biochemical studies indicate neurotoxic changes in the fish brain after imidacloprid exposure [42]. In an experimental toxication study based on the brain tissue of rats, severe lesions, such as the degeneration and necrosis in neurons, have been found after DLM (deltamethrin) exposure [43].

In our study, the acute toxic concentration of CPF induces highly degenerative changes in the neuronal cells of the telencephalon region as compared to IDC and associated swimming behavior. Although various possible mechanisms of CPF and IDC in the brain tissues of targeted and non-targeted aquatic animals were assumed, potential mechanisms are that the $\mathrm{CPF}$ inhibits $\mathrm{AChE}$ irreversibly, whereas the IDC inhibits AChE reversibly. Another inducing mechanism may be speculated that the molar mass of CPF $(350.59 \mathrm{~g} / \mathrm{mol})$ is lesser than the molar mass of IDC (527.8 $\mathrm{g} / \mathrm{mol}$ ). Therefore, CPF easily crosses the blood-brain barrier and cause severe degenerative and behavioral changes in brain tissue. Furthermore, IDC does not cross the blood-brain barrier easily and cause less neurodegenerative and behavioral changes.

In the present study, alteration in locomotory behavior with decreased rotational locomotory movements was observed, which might be related to histopathological lesions in neuronal cells of the telencephalon. The immunohistological lesions of the telencephalon in zebrafish display alterations of aggressive and swimming behavior after deltamethrin exposure [44]. Previous studies also indicate that the appearance of vacuoles and necrotic cells in the brain after exposure to dietary copper (without measurable increases in brain $\mathrm{Cu}$ content) results in changes in circulating serotonin/melatonin levels and loss of circadian locomotor activity patterns $[45,46]$.

Some researcher believed that the CPF causes persistent neurobehavioral impairment in zebrafish, where tests of sensorimotor response, stress response, and learning were conducted with adult zebrafish after early developmental CPF exposure. The study demonstrated that $\mathrm{CPF}$ caused selective long-term neurobehavioral alterations in zebrafish [47]. In another study, a significant decrease in whole-brain activity of zebrafish after exposure to CPF was noted [48]. Additionally, CPF exposure caused a $20 \%$ reduction in the sensory function in juvenile Coho salmon (Oncorhynchus kisutch), which can be recognized for its neurotoxic effects [49]. Likewise, CPF also induced neurotoxicity in two different fish species, Cnesterodon decemmaculatus and Cheirodon interruptus [50].

Previously, the toxicity of IDC induces behavioral and morphological abnormalities in C. carpio, including dark 

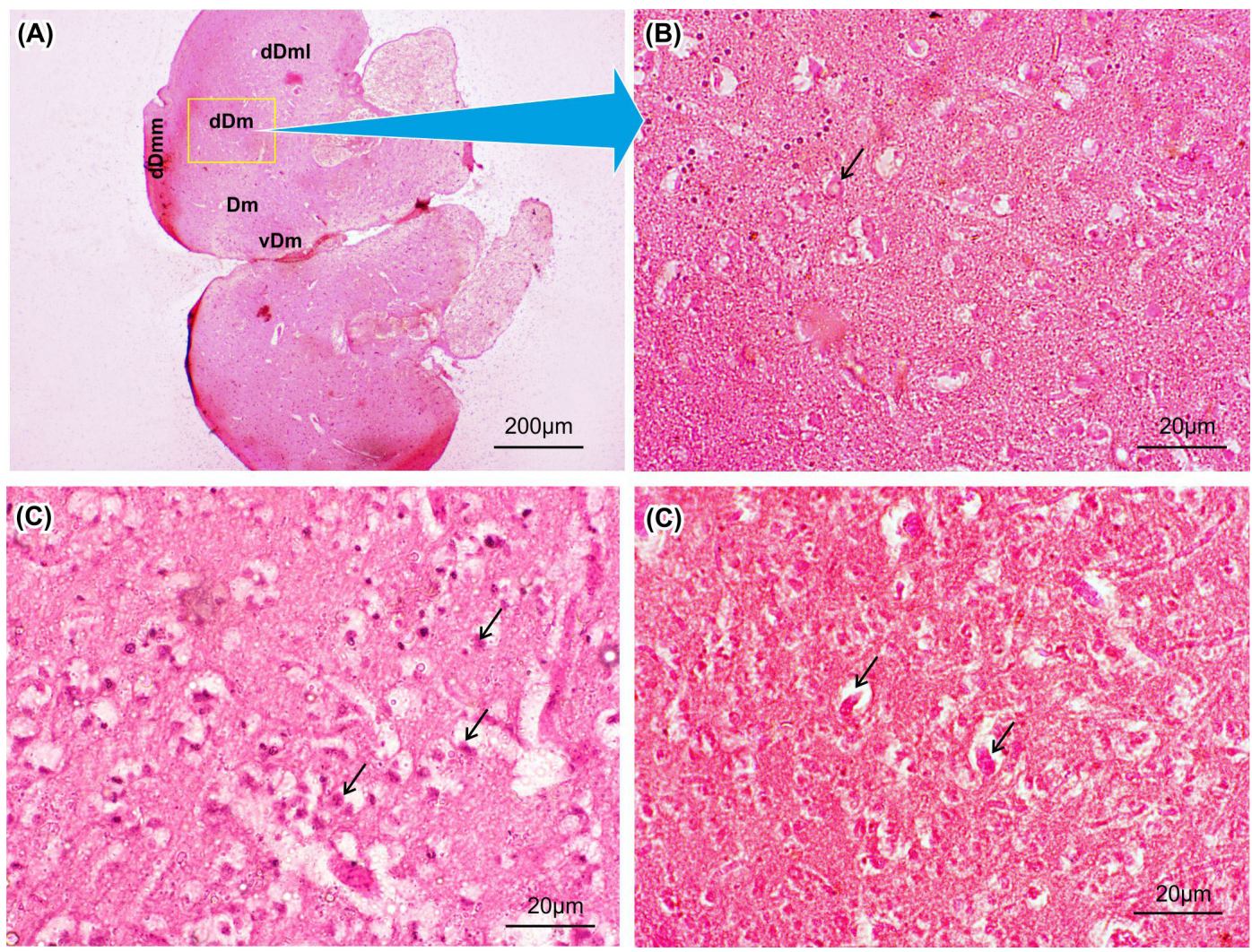

Figure 5: Effect of acute toxicity of CPF and IDC on dDm of telencephalon region of fish brain, H. fossilis, at 96 hours. Photograph A shows the telencephalon region of control fish brain at a low magnification $(40 \times)$ (scale bar $=200 \mu \mathrm{m})$. Microphotograph B shows normal neuronal cells (arrowhead) of the dDm of telencephalon of the control fish brain at a high magnification (400×). Microphotograph C shows highly vacuolized (arrowhead) and degenerative neuronal cells after

CPF exposure. Microphotograph D shows mild neurodegeneration (arrowhead) after IDC exposure (scale bar $=20 \mu \mathrm{m}$; magnification $=400 \times)($ Dm, pars dorsalis; $\mathrm{dDm}$, dorsal pars medialis; dDmm, medial portion of dDm; dDml, lateral portion of dDm; vDm, ventral region of Dm).

coloration, unilateral or bilateral exophthalmia, loss of equilibrium, lateral swimming near the surface, motionless on the bottom of the tank, hyper excitement, and lethargy [34]. Meanwhile, the lethal and sublethal concentrations of IDC exposure induce behavioral abnormality, including swimming near the water surface, hyperexcitability, muscular incoordination, hyperactivity, erratic movement, loss of buoyancy, increased gill mucus secretion, and restlessness before death [5]. The alteration in the behavior of Labeo rohita is also related to decreased glycogen and protein level in fish brain tissue after IDC exposure [51]. The abnormalities in locomotory behavior might also be related to energy production failure or the release of stored metabolic energy due to low food intake [52]. Previously, our laboratory established the acute toxicity of CPF on the degeneration of neuronal cells in the optic tectum and cerebellar region of the fish brain with alterations in locomotory behavior of $H$. fossilis [53].

\section{CONCLUSION}

The present study concludes that acute $(1.92 \mathrm{mg} / \mathrm{l}$ or LC50) and short exposure (24-96 hours) of CPF-induced histopathological changes in neuronal cells of the telencephalon region results in abnormal locomotory behavioral responses in $H$. fossilis under laboratory environment. On the contrary, an equivalent dose $(0.075$ $\mathrm{mg} / \mathrm{l}$ or $\mathrm{LC}_{50}$ ) of IDC could not induce severe pathological changes in the telencephalon area of the fish brain, followed by mild irregular and less powerful swimming/locomotory performances in a non-target fish species. Moreover, IDC was found to be less toxic than CPF. Hence, IDC could be an alternate choice of the $\mathrm{CPF}$ at equal concentrations.

\section{ACKNOWLEDGMENTS}

The authors are obliged to the Head of the Department of Zoology, University of Allahabad, Prayagraj, India, for providing laboratory facilities and UGC-CRET, UoA for financial assistance. The authors are also thankful to Dr. Jyoti Verma for providing a photomicrography facility.

\section{AUTHOR CONTRIBUTIONS}

All authors made substantial contributions to conception and design, acquisition of data, or analysis and interpretation of data; took part in drafting the article or revising it critically for important intellectual content; agreed to submit to the current journal; gave final approval of the version to be published; and agree to be accountable for all aspects of the work. All the authors are eligible to be an author as per the international committee of medical journal editors (ICMJE) requirements/ guidelines.

\section{CONFLICTS OF INTEREST}

The authors report no financial or any other conflicts of interest in this work. 


\section{PUBLISHER'S NOTE}

This journal remains neutral with regard to jurisdictional claims in published institutional affiliation.

\section{REFERENCES}

1. Karen DJ, Li W, Harp, PR, Gillette JS, Bloomquist JR. Striatal dopaminergic pathways as a target for the insecticides cypermethrin and chlorpyrifos. Neurotoxicology 2001;22:811-7.

2. Pathiratne A, Chandrasekera LW, De Seram PK. Effects of biological and technical factors on brain and muscle cholinesterases in Nile tilapia, Oreochromis niloticus: implications for biomonitoring neurotoxic contaminations. Arch Environ Contam Toxicol 2008;54:309-17.

3. Yen J, Donerly S, Levin ED, Linney EA. Differential acetylcholinesterase inhibition of chlorpyrifos, diazinon and parathion in larval zebrafish. Neurotoxicol Teratol 2011;33:735-41.

4. Taheri Mirghaed A, Ghelichpour M. Determination of lethal concentrations of indoxacarb in fingerling Cyprinus carpio at two temperatures. J Innov Stud Aquat Biol Fish 2015;3:339-45.

5. Taheri Mirghaed A, Ghelichpour M, Mirzargar SS, Joshaghani H, Ebrahimzadeh Mousavi H. Plasma proteins, hepatic enzymes, thyroid hormones and liver histopathology of Cyprinus carpio (Linnaeus, 1758) exposed to an oxadiazin pesticide, indoxacarb. Aquac Res 2018;48(11):5666-76.

6. Xing H, Li S, Wang Z, Gao X, Xu S, Wang X. Histopathological changes and antioxidant response in brain and kidney of common carp exposed to atrazine and chlorpyrifos. Chemosphere 2012;88:377-83.

7. Mishra A, Devi Y. Histopathological alterations in the brain (optic tectum) of the fresh water teleost Channa punctatus in response to acute and subchronic exposure to the pesticide chlorpyrifos. Acta Histochem 2014;116:176-81.

8. Altun S, Ozdemir S, Arslan S. Histopathological effects, responses of oxidative stress, inflammation, apoptosis biomarkers and alteration of gene expressions related to apoptosis, oxidative stress, and reproductive system in chlorpyrifos exposed common carp (Cyprinus carpio L.). Environ Pollut 2017;230:432-43.

9. Ware GW. Pesticides: theory and application. In: Reddy S, Ghanathy V, Reddy SLN, Shankaraiah K (eds.). Neurotoxic effects of hexachlorocyclohexane on glycogen metabolism of a teleost fish Channa punctatus, WH Freemann, New York, NY, p 308, 1993.

10. Rao JV, Ghousia B, Pallela R, Usman PK, Nageswara Rao R. Changes in behavior and brain acetylcholinesterase activity in mosquito fish, Gambusia affinis in response to the sub-lethal exposure to chlorpyrifos. Int J Environ Res Public Health 2005;2(3):478-83.

11. Aoki T, Kinoshita M, Aoki R, Agetsuma M, Aizawa H, Yamazaki $\mathrm{M}$, et al. Study the effect of chlorpyrifos on Acetylcholinsterase and haematological response in fresh water fish Channa punctatus. IIOABZ 2012;3(5):12-8.

12. Braithwaite V. Do fish feel pain? Oxford University Press, Oxford, UK, 2010

13. Friedrich RW, Jacobson GA, Zhu P. Circuit neuroscience in zebrafish. Curr Biol 2010;20(8):371-81.

14. Nieuwenhuys R. The comparative anatomy of the actinopterygian forebrain. J Hirnforsch 1963;7:171-92.

15. Alunni A, Blin M, Deschet K, Bourrat F, Vernier P, Rétaux S. Cloning and developmental expression patterns of Dlx2, Lhx 7 and Lhx9 in the medaka fish (Oryzias latipes). Mech Dev 2004;121(7-8):977-83.

16. Kage T, Takeda H, Yasuda T, Maruyama K, Yamamoto N, Yoshimoto $\mathrm{M}$, et al. Morphogenesis and regionalization of the medaka embryonic brain. J Comp Neurol 2004;476(3):219-39.

17. Rodríguez F, López JC, Vargas, JP, Gómez Y, Broglio C, Salas C. Conservation of spatial memory function in the pallial forebrain of amniotes and ray-finned fishes. J Neurosci 2002;22:2894-903.

18. Nordgreen J, Horsberg TE, Ranheim B, Chen ACN. Somatosensory evoked potentials in the telencephalon of Atlantic salmon (Salmo salar) following galvanic stimulation of the tail. J Comp Physiol A 2007:193:1235-42.

19. Berntssen MHG, Aatland A, Handy RD. Chronic dietary mercury exposurecauses oxidative stress, brain lesions, and altered behaviour in Atlantic salmon (Salmo salar) parr. Aquat Toxicol 2003;65:55-72.

20. Bond CE. Biology of fishes, Sounder College Publishing, Orlando, FL, pp 241-58, 1996.

21. Northcutt RG, Davis RE. Telencephalic organization in ray-finned fishes. In Davis RE, Northcutt RG (eds.). Fish neurobiology Vol. 2. Higher brain areas and functions. University of Michigan Press, Ann Arbor, MI, pp 203-36, 1983

22. Wullimann MF. The central nervous system. In Evans DH, Currie $S$ (ed.). The physiology of fishes, CRC press, Boca Raton, FL, pp 245 82, 1998.

23. Savage GE. The fish telencephalon and its relation to learning. In Ebbesson SOE (ed.). Comparative neurology of the telencephalon, Plenum, New York, NY, pp 129-74, 1980.

24. Overmier JB, Hollis KL. Fish in the think tank: Learning, memory and integrated behavior. In Kesner RP, Olton DS (eds.). Neurobiology of comparative cognition, Lawrence Erlbaum Associates, Hillsdale, MI, pp 204-36, 1990.

25. Salas C, Broglio C, Durán E, Gómez A, Ocaña FM, Jiménez-Moya F. Neuropsychology of learning and memory in teleost fish. Zebrafish 2006;3(2):157-71.

26. Gerhardt A, Carlsson A, Ressemann C, Stick KP. A new online biomonitoring system for Gammarus pulex (L.): in situ test below a copper effluent in South Sweden. Environ Sci Technol 1998;32: $105-56$.

27. Van der Schalie WH, Shedd TR, Knechtges PL, Widder MW. Using higher organisms in biological early warning systems for real-time toxicity detection. Biosens Bioelectron 2001;16:457-65.

28. Olla BL, Bejda AJ, Pearson WH. Effects of oiled sediment on the burrowing behavior of the hard clam, Mercenaria mercenaria. Mar Environ Res 1983;9:183-93.

29. Byrne PA, O'Halloran J. The role of bivalve molluscs as tools in estuarine sediment toxicity testing: a review. Hydrobiologia 2001;465:209-17.

30. Kavitha P, Venkateswara Rao J. Toxic effects of chlorpyrifos on antioxidant enzymes and target enzyme acetylcholinesterase interaction in mosquito fish, Gambusia affinis. Environ Toxicol Pharmacol 2008;26:192-8

31. Tilton FA, Bammler TK, Gallagher EP. Swimming impairment and acetylcholinesterase inhibition in zebrafish exposed to copper or chlorpyrifos separately, or as mixtures. Comp Biochem Physiol C 2011b;153:9-16.

32. Jin Y, Zhang X, Shu L, Chen L, Sun L, Qian H, et al. Oxidative stress response and gene expression with atrazine exposure in adult female zebrafish (Danio rerio). Chemosphere. 2010;78:846-52.

33. Bonifacio AF, Cazenave J, Bacchetta C, Ballesteros ML, Bistoni MA, Amé MV, et al. Alterations in the general condition, biochemical parameters and locomotor activity in Cnesterodon decemmaculatus exposed to commercial formulations of chlorpyrifos, glyphosate and their mixtures. Ecol Indic 2016;67:88-97.

34. Bantu N, Kumar RK, Vakita V. Acute toxicity and Respiratory responses in freshwater fish, Labeo rohita exposed to an agrochemical indoxacarb. Innorignal Int J Sci 2017;4(6):2349-7041.

35. Meyers TR, Hendricks JD. Histopathology. In: Loux DB, Dorfman M (eds.). Fundamentals of aquatic toxicology: methods and applications, Hemisphere, Scottsdale, AZ, pp 283-330, 1985.

36. Marchand MJJ, Van Dyk C, Pieterse GM, Barhoorn IEJ, Borman MS Histopathological alterations in the liver of the sharptooth catfish Clarias gariepinus from polluted aquatic ecosystems in South Africa. Environ Toxicol 2009;24(2):133-47.

37. Ito $\mathrm{H}$, Ishikawa $\mathrm{Y}$, Yoshimoto M, Yamamoto N. Diversity of brain morphology in teleosts: brain and ecological niche. Brain Behav Evol 2007;69:76-86. 
behavior of a catfish, Heteropneustes fossilis 2021;9(03):137-143

38. Sarma Dam J, Kenyon LC, Hingley ST, Shindler KS. Mechanisms of primary axonal damage in a viral model of multiple sclerosis. J Neurosci 2009;29:10272-80.

39. Arslan H, Ozdemir S, Altun S. Cypermethrin toxication leads to histopathological lesions and induces inflammation and apoptosis in common carp (Cyprinus carpio L.). Chemosphere. 2017b;180:491-9.

40. Al-Bairuty GA, Shaw BJ, Handy RD, Henry TB. Histopathological effects of waterborne copper nanoparticles and copper sulphate on the organs of rainbow trout (Oncorhynchus mykiss). Aquat Toxicol 2013;126:104-15.

41. Xing H, Li S, Wang Z, Gao X, Xu S, Wang X. Histopathological changes and antioxidant response in brain and kidney of common carp exposed to atrazine and chlorpyrifos. Chemosphere 2012;88:377-83.

42. Topal A, Alak G, Ozkaraca M, Yeltekin AC, Comaklı S, Ac1l G et al. Neurotoxic responses in brain tissues of rainbow trout exposed to imidacloprid pesticide: assessment of 8-hydroxy-2-deoxyguanosine activity, oxidative stress and acetylcholinesterase activity. Chemosphere 2017;175:186-91.

43. Tayebati SK, Tullio MAD, Ricci A, Amenta F. Influence of dermalexposure to the pyrethroid insecticide deltamethrin on rat brain microanatomy and cholinergic/dopaminergic neurochemistry. Brain Res 2009;1301:180-8.

44. Strungaru SA, Plavan G, Ciobica A, Nicoara M, Robea MA, Solcan $\mathrm{C}$, et al. Toxicity and chronic effects of deltamethrin exposure on zebrafish (Danio rerio) as a reference model for freshwater fish community. Ecotoxicol Environ saf 2019;171:854-62.

45. Handy RD. Chronic effects of copper exposure versus endocrine toxicity: two sides of the same toxicological process? Comp Biochem Physiol A Mol Integr Physiol 2003;135:25-38.

46. Campbell HA, Handy RD, Sims DW. Increased metabolic cost of swimming and consequent alterations to circadian activity in rainbow trout (Oncorhynchus mykiss) exposed to dietary copper. Can J Fish Aquat Sci 2002;59:768-77.

47. Sledge D, Yen J, Morton T, Dishaw L, Petro A, Donerly S, et al Critical duration of exposure for developmental chlorpyrifos-induced neurobehavioral toxicity. Neurotoxicol Teratol 2011;33(6):742-51.
48. Eddins D, Cerutti D, Williams P, Linney E, Levin ED. Developmental chlorpyrifos causes behavioral and neurochemical defects in zebrafish Neurotoxicol Teratol 2010;32:99-108.

49. Sandahl JF, Baldwin DH, Jenkins JJ, Scholz NL. Odor-evoked field potentials as indicators of sublethal neurotoxicity in juvenile Coho salmon (Oncorhynchus kisutch) exposed to copper, chlorpyrifos, or esfenvalerate. Can J Fish Aquat Sci 2004;61:404-413.

50. Bonifacio AF, Ballesteros ML, Bonansea RI, Filippi I, Ame MV, Hued AC. Environmental relevant concentrations of a chlorpyrifos commercial formulation affect two neotropical fish species, Cheirodon interruptus and Cnesterodon decemmaculatus. Chemosphere 2017; 188:486-93.

51. Veeraiah K, Rao S, Dhilleswarao H. Changes in biochemical parameters of freshwater fish Labeo rohita exposed to lethal and sublethal concentrations of indoxacarb. Int J Bioassays 2013;2: 1382-7.

52. Dembele K, Haubruge E, Gaspar C. Concentration effects of selected insecticides on brain acetylcholinesterase in the common carp (Cyprinus carpio L.). Ecotoxicol Environ saf 2000;45:49-54.

53. Mishra AK, Gopesh A, Singh KP. Acute toxic effects of chlorpyrifos on pseudobranchial neurosecretory system, brain regions and locomotory behavior of an air- breathing catfish, Heteropneustes fossilis (Bloch1794). Drug Chem Toxicol 2020; doi:10.1080/014805 45.2020.1762631.

\section{How to cite this article:}

Mishra AK, Gopesh A, Singh KP. Acute toxic effects of chlorpyrifos and indoxacarb on dorsal pars medialis of telencephalon and swimming behavior of a catfish, Heteropneustes fossilis. J Appl Biol Biotech 2021; 9(03): 137-143. 